\title{
Utility of the Color-Coded Duplex Neurosonographic Spectrum in Critically III Children in Resource- Limited Centers: A Case Series
}

\author{
Patrick Caqui-Vilca MD \\ Instituto Nacional De Salud Del Niño San Borja \\ Jesús Dominguez-Rojas MD ( $\nabla$ jesusdominguez24@gmail.com ) \\ Instituto Nacional de Salud del Niño https://orcid.org/0000-0001-6141-6622 \\ Javier Ponce MD \\ Hospital Dr. Guillermo Rawson, Argentina. \\ Gabriel Omar Heredia-Orbegoso MD \\ Hospital Edgardo Rebagliati Martins
}

\section{Case Report}

Keywords: transcranial duplex, pediatrics, intensive care medicine, neurology

Posted Date: September 14th, 2021

DOI: https://doi.org/10.21203/rs.3.rs-898371/v1

License: @ (i) This work is licensed under a Creative Commons Attribution 4.0 International License.

Read Full License 


\section{Abstract}

Ultrasound in pediatric neurocritical care has a wide variety of indications, such as the study of vasospasm in subarachnoid hemorrhage, flow changes in intracranial stenosis, endocranial hypertension and to evaluate some therapeutic measures. The following is a series of five most relevant cases collected from Pediatric Intensive Care with abnormal images in transcranial duplex (TCD) and their typical findings in this type of studies. Transcranial duplex offers a diagnostic method of rapid evaluation that provides reliable information for decision making in pediatric intensive care, but it is a tool with which there is little experience in the country, so these findings are didactic and should be complemented with studies of greater diagnostic relevance.

\section{Introduction}

Since 1975 thanks to the work of Fritz Thurstone and David Phillips from Duke University, the refined and real-time version of Doppler with a two-dimensional ultrasound image called Duplex Doppler was given [1].

Brain injuries and other neurological conditions are frequently encountered in pediatric intensive care units (PICUs) and are the most common proximate causes of death in children admitted to these units, in which severe encephalocranial trauma is prevalent.

Transcranial color-coded duplex sonography (TCCS), unlike conventional transcranial Doppler (TCD) sonography, allows the sonographer to delineate intracranial bony and parenchymal structures, visualize the basal cerebral arteries in color, and measure angle-corrected blood, flow velocities at a specific site in the artery in question. This makes flow velocity measurements more valid than those obtained with conventional TCD [2]. Transcranial color-coded ultrasound (TCCS) allows bedside evaluation of these patients; it is a noninvasive and readily available technique for real-time assessment and monitoring of cerebral blood flow. The following therapeutic interventions are reported as hemodynamic optimization (fluid resuscitation or vasopressor/inotropic administration), de-escalation (discontinuation or dose reduction) of neurological pharmacological treatments such as osmotherapy agents, sedatives and neuromuscular blocking agents, and escalation (initiation, addition, or intensification) of the afore mentioned neurological pharmacological treatments [3].

\section{Clinical Case Presentation}

We report 5 cases of usefulness and teaching with color-coded ultrasound in pediatric critical units, which would help us guide diagnostic and therapeutic management in centers that do not have high-resolution imaging equipment and neurosurgical interventionism, and the decision to be referred to centers of greater complexity.

\section{Case 1}


7-year-old schoolboy suffers fall from 2-meter height. Admitted to our institution with neurological deterioration with Glasgow scale 9 on admission, neuroprotection is provided due to severe encephalic trauma, After 24 hours brain tomography showed infarction in the entire region of the right middle cerebral artery with a small intraparenchymal hematoma with signs of endocranial hypertension, then subjected to right decompressive craniectomy and hard plasty with placement of left intraparenchymal pressure sensor, no pulse waves were visualized. After 36 hours postoperatively, anisocoria was evidenced due to third cranial nerve lesion, endovascular therapy was not performed and he did not receive anticoagulation due to hematoma. Transcranial color-coded duplex (TCCS) was performed and no flow was found in the right middle cerebral artery compatible with probable thrombosis of the right middle cerebral artery with decreased average velocities and high pulsatility indices in the left middle cerebral artery and basilar artery compatible with hypoperfusion due to high progressive cerebrovascular resistance, He was induced to barbiturate coma and monitored with TCCS and with adequate hemodynamics, cerebral angiography with reconstruction was performed, finding thrombosis of the right middle cerebral artery with decreased cerebral edema compared to admission. After 6 days he was extubated with left hemiplegia, currently with home physical therapy [Figure 1].

\section{Case 2}

16-year-old male schoolboy admitted to pediatric intensive care for refractory status epilepticus. On admission, cerebral tomography without contrast shows mild cerebral edema without intraparenchymal bleeding. Transcranial color-coded duplex scan (TCCS) shows vessels dependent on the M2 segment of the middle cerebral artery with multicolor pattern in different shades of blue and red corresponding to different directions of blood flow compatible with an arteriovenous malformation, then underwent cerebral panangiography and embolization confirming the finding of arteriovenous malformation dependent on the middle cerebral artery [Figure 2].

\section{Case 3}

10-year-old male schoolboy suffers severe traumatic injury due to a traffic accident. Brain tomography on hospital admission shows laminar epidural hematoma in the right frontal region with small hemorrhagic contusions in the frontal region and global edema. Intracranial pressure sensor registers ICP $<20 \mathrm{mmhg}$. 24 hours after admission, he presented sudden neurological deterioration associated with mydriasis, bradycardia and arterial hypertension above the 95th percentile, he was stabilized in the emergency room and then admitted to the operating room due to rebleeding in cerebral tomography with severe endocranial hypertension, it was decided to evacuate the hematoma and decompressive craniectomy plus right duroplasty, Upon admission to the pediatric intensive care unit, the patient showed clinical signs of encephalic death, for which transcranial color-coded duplex (TCCS) was performed under lowdose sedation and analgesia. Reverberant flow spectra (cerebral circulatory arrest pattern) were observed in both middle cerebral arteries and basilar artery, then isolated systolic spikes and mortality were observed after 98 hours of hospital admission [Figure 3].

\section{Case 4}


School girl, 7 years old, female, admitted for severe headache and vomiting of 72 hours of evolution, Glasgow scale 14. On admission, cerebral tomography with angiography was performed, showing subarachnoid hemorrhage Fisher II scale, probable aneurysmal origin, in transcranial color-coded duplex (TCCS) on admission, right MCA showed mean velocity $72 \mathrm{~cm} / \mathrm{s}$ with pulsatility index 0.62 , left MCA showed mean velocity $70 \mathrm{~cm} / \mathrm{s}$ with pulsatility index $0.60,24$ hours after admission the MV of the right MCA was elevated from $72 \mathrm{~cm} / \mathrm{s}$ to $110.3 \mathrm{~cm} / \mathrm{s}$ and there was no variation in velocities of the left MCA, ipsilateral/contralateral MCA index $>1.5$, Lindegaard index $>3$ (3.8-4.2) compatible with mild vasospasm so nimodipine was started in continuous infusion, the next day panangiography and embolization of 4 $\mathrm{mm}$ aneurysm located in the anterior communicating artery, with favorable evolution [Figure 4].

\section{Case 5}

13 year old school girl, suffers severe traumatic brain injury due to traffic accident, GSC 8 points, brain tomography shows global brain edema, no bleeding, monitor intraparenchymal pressure of $30 \mathrm{mmHg}$, in transcranial color-coded Duplex, shows pattern of low velocity and high resistance in anterior circulation and posterior circulation pattern of high pulsatility without hypoperfusion, received bolus of $3 \%$ hypertonic solution followed by infusion at $1 \mathrm{ml} / \mathrm{kg} /$ hour and optimization of sedoanalgesia. Controls with color-coded transcranial Duplex, improvement of flow velocities and progressive decrease of pulsatility index until normalization [Figure 5].

\section{Discussion}

Color-coded transcranial Duplex, a noninvasive real-time method, can be used as a pediatric bedside tool to identify compromised intracranial hemodynamics. Its utility is described to identify blood flow more reliably in specific intracranial vessel segments; allows for more detailed assignment of vascular pathologies; and offers the opportunity for angle correction, resulting in more accurate measurement of flow velocities [4].

In case 1 with color-coded transcranial duplex evaluation, it is reliable and noninvasive of patients with cerebral artery stenosis becomes feasible, avoiding the potential adverse effects of cerebral angiography. Transcranial ultrasound provides reliable assessment of cross-flow through the circle of Willis and stenosis, occlusions and vasospasm of the main basal cerebral arteries. It also identifies intracranial hemorrhage but is inferior to neuro radiological techniques [5].

In patients with traumatic brain injury with endocranial hypertension, transcranial Doppler can be a useful tool to estimate cerebral perfusion pressure in a noninvasive manner, and there are studies that show a good correlation between invasive and noninvasive determination of cerebral perfusion pressure [12]. On the other hand, attempts have also been made to estimate intracranial pressure from the pulsatility index, with a good correlation [13]. Transcranial Doppler could not only be useful in the diagnosis of increased intracranial pressure, but also in its follow-up, which is demonstrated through changes in the morphology of the spectral wave, where there is a progressive decrease mainly in the velocities at the end of diastole 
and a tendency to systolicization of the spectral wave, finally reaching patterns of encephalic death [12], [14],[15],[16],[17],[18].

One of the most notable advantages of CВCT over blind Doppler is that the direction of blood flow can be precisely known and thus align the ultrasound beam as close as possible to an angle of zero degrees with respect to the direction of the erythrocytes, obtaining the velocities with great precision [19],[20],[21], [23]. DCT not only has the advantage of obtaining accurate blood flow velocities in the vessels of the polygon of Willis but also provides information about any structural or pathophysiological anatomical alteration of the skull base vessels [20]. In addition, this technique allows insonation of segments of cranial vessels inaccessible by conventional Doppler through the temporal window (e.g., insonation of segment A2 of the anterior cerebral artery) [22].

In case 2 we describe TCCS as a valuable method for the detection and follow-up of hemodynamic changes of AVM in children, before and after treatment, but further studies are needed to establish the benefits of this approach, for the use of color-coded transcranial duplex ultrasound (TCCS). As mentioned above, DCT not only has the advantage of obtaining more accurate erythrocyte velocities, but also provides information about any structural anatomical alteration of the blood vessels [20].

In case 3 we describe sonographic findings of cerebral circulatory arrest. Color-coded duplex ultrasonography and CT angiography have recently been incorporated in the fourth update of the German Medical Association guidelines for the determination of irreversible cessation of brain function ("brain death"), as of July 2015 [6].

Although the diagnosis of encephalic death is clinical [24], on some occasions the clinical examination cannot be performed, as in cases of severe facial trauma or in situations where it is impossible to perform the apnea test, it is in these cases where ancillary tests become fundamental tools for making the diagnosis of encephalic death [24],[25]. Within the ancillary tests, cerebral angiography is one of the tools with the greatest diagnostic certainty and when CDCT was compared with cerebral angiography, CDCT was a sensitive tool for diagnosing brain death, offering a reliable alternative to cerebral angiography [26].

Case 4 describes TCCS signs of cerebral vasospasm and finding of cerebral aneurysm. TCCS is useful for the detection and follow-up of intracranial vasospasm, can visualize larger supratentorial hematomas with subcortical localization and hemorrhagic transformation of ischemic infarcts, and provides incidental detection of cerebral aneurysms and arteriovenous malformations [7]. Findings in cerebral occlusive disease, TCCS provides information on the location of the stenosis. An increase in flow velocity is also measured in the case of vasospasm [8]. It should be noted that the reliability to detect the real magnitude of the velocities is much more accurate with СBCT than with blind Doppler, however it should be noted that the Lindergard Index was described by this author with a $2 \mathrm{MHz}$ transducer, both to insonate 
the midbrain and to insonate the extracranial portion of the ipsilateral internal carotid [27],[28]; this frequency may vary slightly when performing CBCT.

Case 5 Intracranial hypertension is described using color Doppler can localize intracranial vessels and simplifies the acquisition of the pulsed wave Doppler spectrum. Elevation of the pulsatility index may be useful as a diagnostic support tool when very high intracranial pressure or cerebral hypoperfusion is suspected [9].

The intracranial arteriovenous index is a reliable parameter that can be used to assess vasospasm after subarachnoid hemorrhage. Its reliability in differentiating vasospasm and hyperperfusion is slightly higher than that of the established Lindegaard index, and this method has the additional advantage of a markedly lower failure rate [10].

An aneurysm is visualized as a color-coded appendage next to a normal vessel. The most typical colorcoded feature is the presence of two areas with inversely directed flow: half of the aneurysm is colorcoded blue and the other half is color-coded red, with the colors corresponding to the direction of blood inflow and outflow [11].

The early use of TCCS (within $24 \mathrm{~h}$ of admission), its status as a first line neuromonitoring tool, and the frequency of use during night shifts highlighted the immediate availability of this technique. Thus, TCCS has the potential to become an influential neuromonitoring strategy in the PICU.

\section{Conclusions}

Color-coded transcranial duplex is useful in the face of diagnostic suspicion of cerebral vascular events in critically ill children and allows us to guide our surgical medical conduct. Although it is not superior to high resolution sonographic imaging studies, nevertheless, it adds to the studies for an adequate diagnosis.

\section{Declarations}

Conflict of Interest Disclosures: The authors have indicated they have no conflicts of interest to this article to disclose.

Abbreviations: Transcranial color-coded duplex sonography (TCCS), pediatric intensive care units (PICUs),

Funding / Support: No funding was secured for this study.

Table of Contents Summary: Case Series description of Transcranial Duplex

All authors conceptualized the manuscript, performed data acquisition, drafted the initial manuscript, and critically reviewed the manuscript. 
All authors approved the final manuscript as submitted and agree to be accountable for all aspects of the work.

The authors declare that the manuscript "Utility of the color-coded duplex neuropsychographic spectrum in critically ill children in resource-limited centers: a case series" has the approval of the institution's ethics committee study. Parental approval for publication and dissemination of the manuscript has been obtained.

\section{References}

1. Donato Salas Segura. La historia del uso del efecto Doppler en medicina. Acta académica mayo 2002.

2. Krejza, J., \& Baumgartner, R. W. (2004). Clinical Applications of Transcranial Color-Coded Duplex Sonography. Journal of Neuroimaging, 14(3), 215-225. doi:10.1111/j.1552-6569.2004.tb00241.x

3. Virginie Rollet-Cohen, Philippe Sachs, Transcranial Doppler Use in Non-traumatic Critically III Children: A Multicentre Descriptive Study. July 2021Frontiers in Pediatrics: 609175. DOI: 10.3389/fped.2021.609175.

4. Max Nedelmann, MD, Erwin Stolz, MD, Tibo Gerriets, MD, Ralf W. Baumgartner, MD, Giovanni Malferrari, MD, Guenter Seidel, MD, Manfred Kaps, MD. Consensus Recommendations for Transcranial Color-Coded Duplex Sonography for the Assessment of Intracranial Arteries in Clinical Trials on Acute Stroke. Volume 40, Issue 10, 1 October 2009; Pages 3238-3244. https://doi.org/10.1161/STROKEAHA.109.555169.

5. RW Baumgartner. [Cerebrovascular ultrasound diagnosis]. Ther Umsch. Julio de 1996; 53 (7): 52834.

6. U Walter. Doppler and Duplex Sonography for the Diagnosis of the Irreversible Cessation of Brain Function ("Brain Death"): Current Guidelines in Germany and Neighboring Countries. Ultraschall Med. 2016 Dec;37(6):558-578. doi: 10.1055/s-0042-112222

7. RW Baumgartner. Transcranial color-coded duplex sonography. J Neurol. 1999 Aug;246(8):637-47. doi: $10.1007 / \mathrm{s} 004150050424$.

8. Eva Bartels. Transcranial color-coded duplex ultrasonography in routine cerebrovascular diagnostics. Perspectives in Medicine. Volume 1, Issues 1-12, September 2012, Pages 325-330.

9. Pablo Blanco, Michael Blaivas. Applications of Transcranial Color-Coded Sonography in the Emergency Department. J Ultrasound Med. 2017 Jun;36(6):1251-1266. doi: 10.7863/ultra.16.04050. Epub 2017 Feb 27.

10. Florian Connolly, MD, Stephan J. Schreiber, MD. Assessment of intracranial venous blood flow after subarachnoid hemorrhage: a new approach to diagnose vasospasm with transcranial color-coded duplex sonography. J Neurosurg 129:1136-1142, 2018.

11. E. Bartels. Evaluación de malformaciones arteriovenosas con ecografía dúplex transcraneal codificada por colores. ¿La ubicación de una MAV influye en su detección ultrasónica? Diario de 
Ultrasonido en Medicina, 24 (2005), pp. 1511-1517.

12. Schmidt EA, Czosnyka M, Gooskens I, et al. Preliminary experience of the estimation of cerebral perfusion pressure using transcranial Doppler ultrasonography. J Neurol Neurosurg Psychiatry. 2001;70(2):198-204

13. Bellner J, Romner B, Reinstrup P, Kristiansson KA, Ryding E, Brandt L. Transcranial Doppler sonography pulsatility index (PI) reflects intracranial pressure (ICP). Surg Neurol. 2004; 62: 45-51

14. Klingelhöfer J, Conrad B, Benecke R, Sander D, Markakis E. Evaluation of intracranial pressure from transcranial Doppler studies in cerebral disease. J Neurol. 1988;235(3):159-62.

15. Czosnyka M, Smielewski P, Timofeev I, et al. Intracranial pressure: more than a number. Neurosurg Focus. 2007;22(5): E10.

16. Cardim D, Robba C, Donnelly J, et al. Prospective study on noninvasive assessment of ICP in head injured patients: comparison of four methods. J Neurotrauma 2015.

17. Schmidt B, Klingelhöfer J, Md J, Schwarze JJ, Sander D, Wittich I. Noninvasive prediction of intracranial pressure curves using transcranial Doppler ultrasonography and blood pressure curves. Stroke. 1997;28:2465-72.

18. Cardim, D. et al. Non-invasive monitoring of intracranial pressure using transcranial doppler ultrasonography: Is it possible?. Neurocrit. Care 25, 473-491 (2016).

19. Eicke BM, Tegeler CH, Dalley G, Myers LG. Angle correction in transcranial Doppler sonography. J Neuroimag 1994;4:29-33

20. Bartels E, Fuchs HH, Flügel KA. Color Doppler imaging of basal cerebral arteries: normal reference values and clinical applications. Angiology. 1995 Oct;46(10):877-84.

21. Baumgartner RW, Mathis J, Sturzenegger M, Mattle HP. A validation study on the intraobserver reproducibility of transcranial color-coded duplex sonography velocity measurements. Ultrasound Med Biol. 1994;20(3):233-7

22. Stolz E, Kaps M, Kern A, Dorndorf W. Frontal bone windows for transcranial color-coded duplex sonography. Stroke. 1999 Apr;30(4):814-20.

23. Lepić T, Veljancić D, Jovanikić O, Lepić M, Slankamenac P, Raicević R. Importance of angle correction in transcranial color-coded duplex insonation of arteries at the base of the brain. Vojnosanit Pregl. 2015 Dec;72(12):1093-7

24. Greer DM, Shemie SD, Lewis A, Torrance S, Varelas P, Goldenberg FD, Bernat JL, Souter M, Topcuoglu MA, Alexandrov AW, Baldisseri M, Bleck T, Citerio G, Dawson R, Hoppe A, Jacobe S, Manara A, Nakagawa TA, Pope TM, Silvester W, Thomson D, Al Rahma H, Badenes R, Baker AJ, Cerny V, Chang C, Chang TR, Gnedovskaya E, Han MK, Honeybul S, Jimenez E, Kuroda Y, Liu G, Mallick UK, Marquevich V, Mejia-Mantilla J, Piradov M, Quayyum S, Shrestha GS, Su YY, Timmons SD, Teitelbaum J, Videtta W, Zirpe K, Sung G. Determination of Brain Death/Death by Neurologic Criteria: The World Brain Death Project. JAMA. 2020 Sep 15;324(11):1078-1097.

25. Rizvi T, Batchala P, Mukherjee S. Brain Death: Diagnosis and Imaging Techniques. Semin Ultrasound CT MR. 2018 Oct;39(5):515-529. 
26. Poularas J, Karakitsos D, Kouraklis G, Kostakis A, De Groot E, Kalogeromitros A, Bilalis D, Boletis J, Karabinis A. Comparison between transcranial color Doppler ultrasonography and angiography in the confirmation of brain death. Transplant Proc. 2006 Jun;38(5):1213-7.

27. Lindegaard KF, Nornes H, Bakke SJ, Sorteberg W, Nakstad P. Cerebral vasospasm after subarachnoid haemorrhage investigated by means of transcranial Doppler ultrasound. Acta Neurochir Suppl (Wien). 1988;42:81-4. doi: 10.1007/978-3-7091-8975-7_16.

28. Lindegaard KF, Nornes H, Bakke SJ, Sorteberg W, Nakstad P. Cerebral vasospasm diagnosis by means of angiography and blood velocity measurements. Acta Neurochir (Wien). 1989;100(1$2): 12-24$

\section{Figures}

Figure 1: Transcranial Duplex Imaging of Case 1

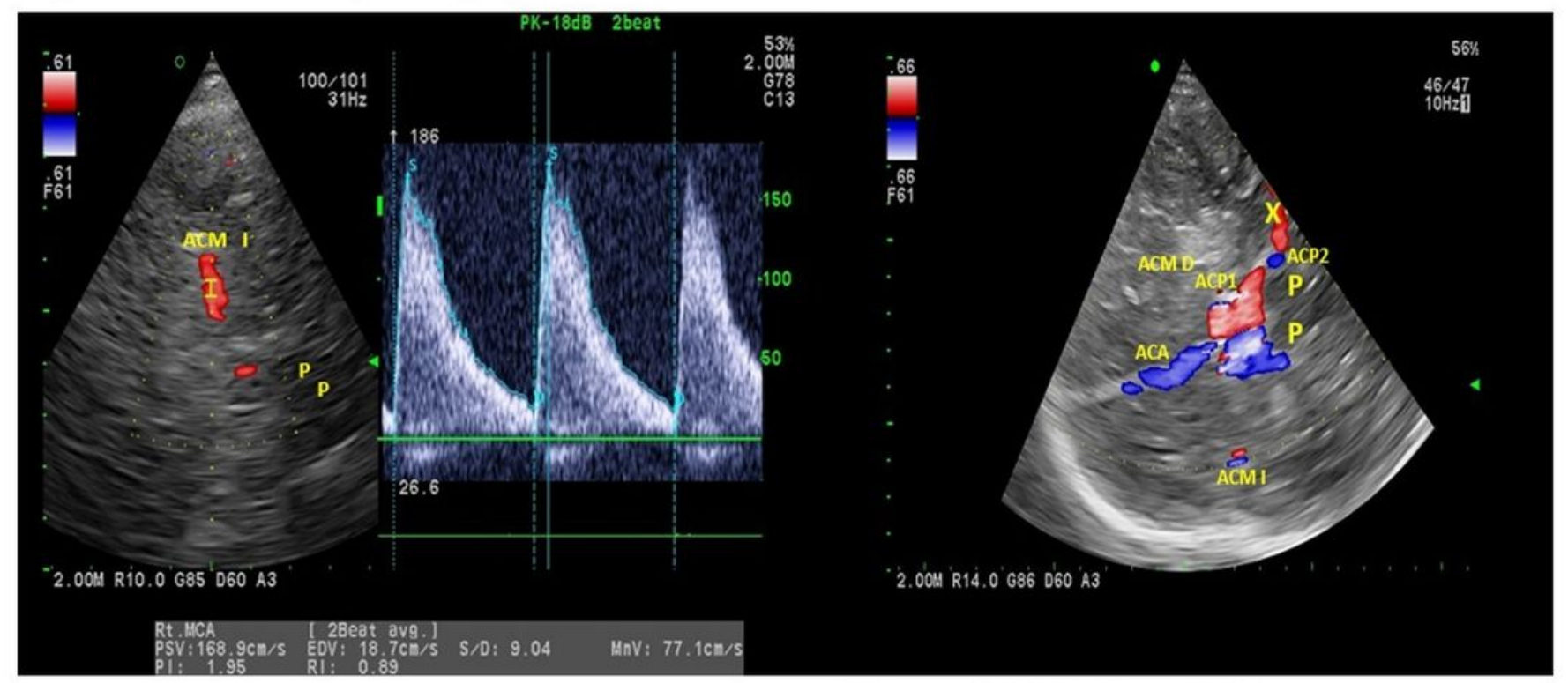

Left middle cerebral artery with decreased mean velocity $77.1 \mathrm{~cm} / \mathrm{s}$

No flow seen in right middle cerebral artery with elevated pulsatility index 1.95: hypoperfusion due to high cerebrovascular resistance.

LMCA:left middle cerebral artery P:cerebral peduncle MnV:mean velocity IP:pulsatility index.

$\mathrm{RCA}$ : right middle cerebral artery

LMCA: left middle cerebral artery

PCA1:posterior communicating artery segment $P 1$

ACP2:posterior communicating artery segment $P 2$

$A C A$ :right anterior cerebral artery

$\mathrm{X}$ : perforating artery dependent on the posterior cerebral artery.

\section{Figure 1}

Left middle cerebral artery with decreased mean velocity $77.1 \mathrm{~cm} / \mathrm{s}$ with elevated pulsatility index 1.95 : hypoperfusion due to high cerebrovascular resistance. LMCA:left middle cerebral artery P:cerebral peduncle MnV:mean velocity IP:pulsatility index. 
Figure 2: Transcranial Duplex Imaging of Case 2

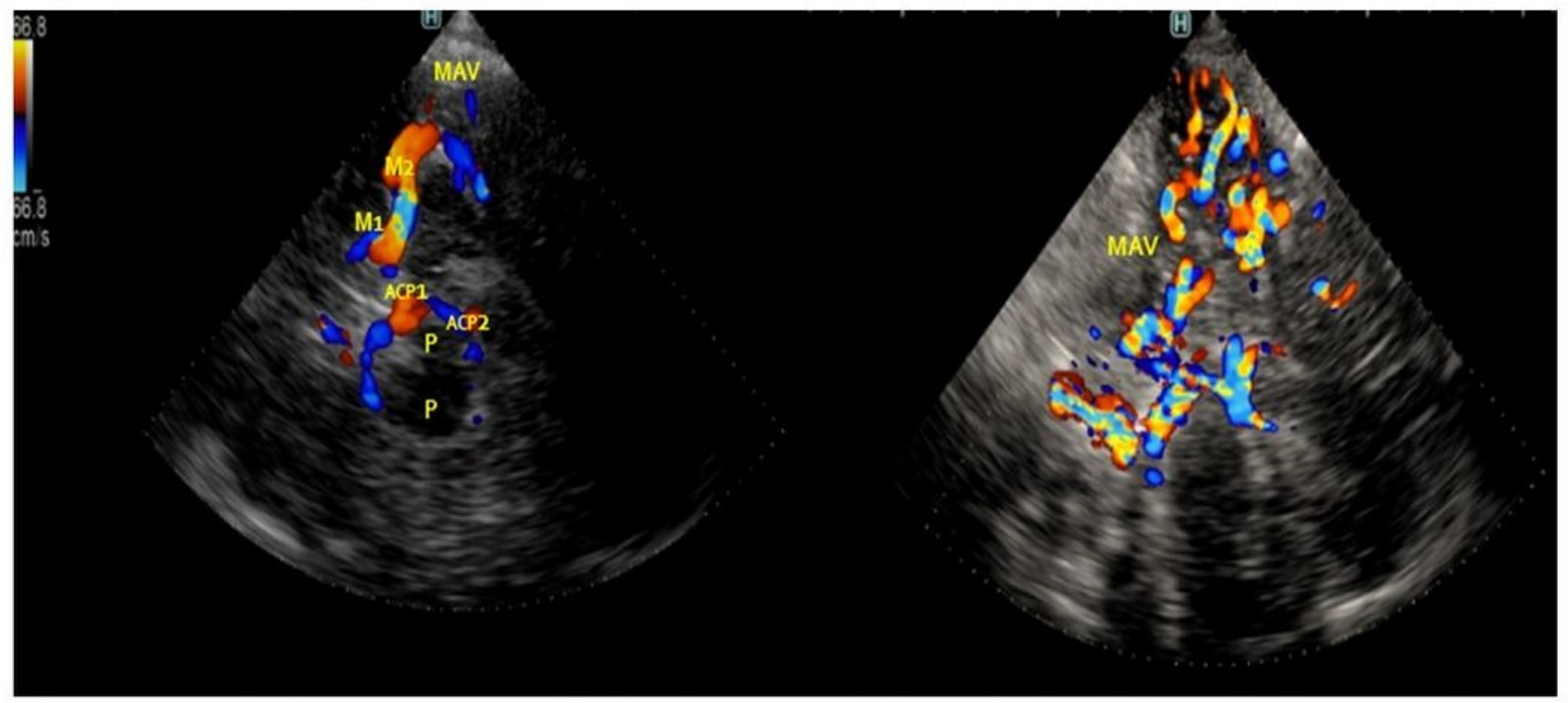

There are vessels that appear as a multicolored pattern in different shades of blue and red corresponding to the different directions of blood flow, these vessels are dependent on the $M 2$ segment of the middle cerebral artery compatible with an arteriovenous malformation. AVM: arteriovenous malformation M1: M1 segment of the middle cerebral artery M2: M2 segment of the middle cerebral artery PCA1: P1 segment of the posterior cerebral artery PCA2: P2 segment of the posterior cerebral artery P: cerebral peduncle.

\section{Figure 2}

There are vessels that appear as a multicolored pattern in different shades of blue and red corresponding to the different directions of blood flow, these vessels are dependent on the M2 segment of the middle cerebral artery compatible with an arteriovenous malformation. AVM: arteriovenous malformation M1: M1 segment of the middle cerebral artery M2: M2 segment of the middle cerebral artery PCA1: P1 segment of the posterior cerebral artery PCA2: P2 segment of the posterior cerebral artery P: cerebral peduncle. 
Figure 3: Transcranial Duplex Imaging of Case 3

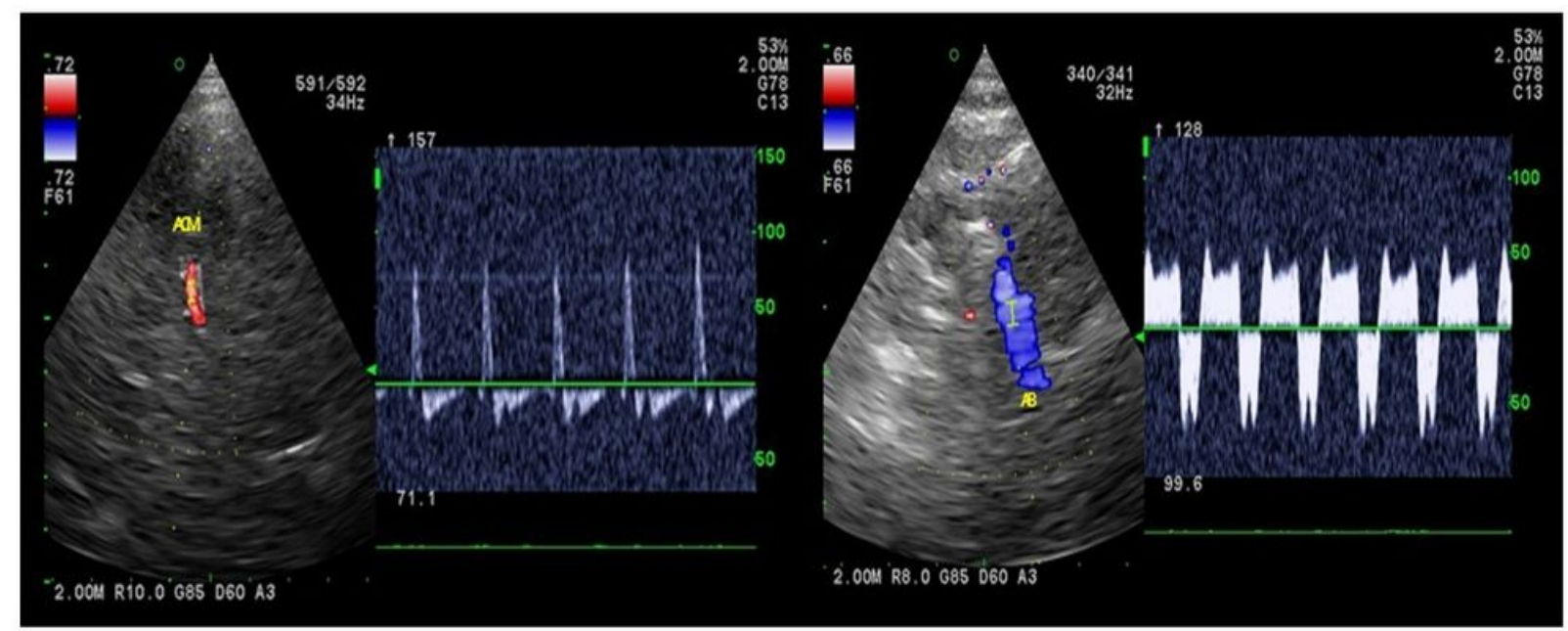

In both middle cerebral arteries and in the basilar artery there are spectra of cerebral circulatory arrest pattern: reverberant flow, i.e. the flow advances very slowly in the systolic stage and recedes in the diastolic stage.

MCA: middle cerebral artery $A B$ : basilar artery.

\section{Figure 3}

In both middle cerebral arteries and in the basilar artery there are spectra of cerebral circulatory arrest pattern: reverberant flow, i.e. the flow advances very slowly in the systolic stage and recedes in the diastolic stage. MCA: middle cerebral artery AB: basilar artery. 
Figure 4: Transcranial Duplex Imaging of Case 4

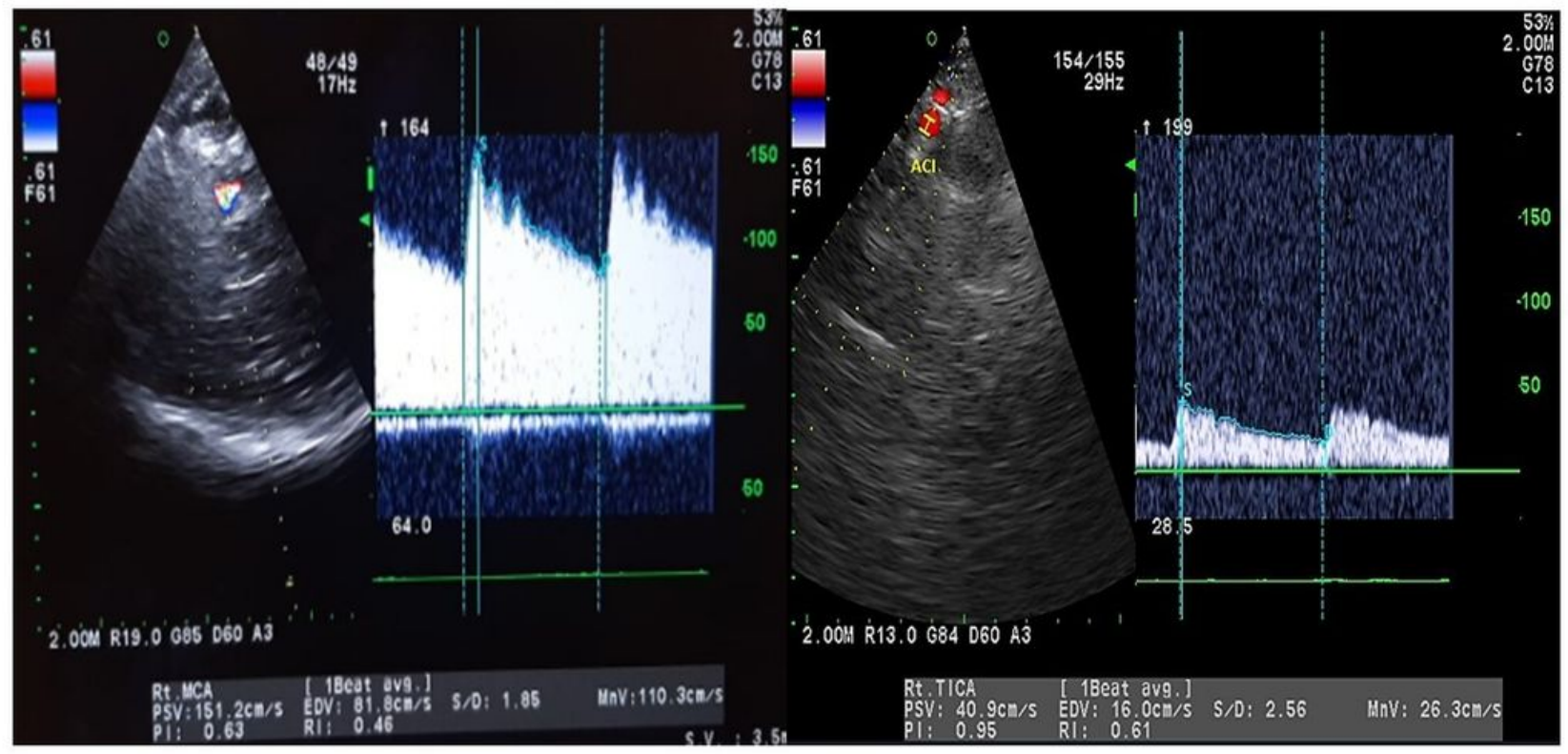

DTCC of right MCA (MV:110.3 cm/sg,IP:0.63) and ICA in its ipsilateral extracranial portion (MV:26.3 $\mathrm{cm} / \mathrm{sg}, \mathrm{IP}: 0.95)$ lindergaard index 4.19, it should be noted that the insonation of the MCA and ICA in its extracranial portion were made with a $2 \mathrm{MHZ}$ frequency.

\section{Figure 4}

DTCC of right MCA (MV: $110.3 \mathrm{~cm} / \mathrm{sg}, \mathrm{IP}: 0.63)$ and ICA in its ipsilateral extracranial portion (MV:26.3 $\mathrm{cm} / \mathrm{sg}, \mathrm{IP}: 0.95$ ) lindergaard index 4.19 , it should be noted that the insonation of the MCA and ICA in its extracranial portion were made with a $2 \mathrm{MHZ}$ frequency. 
Figure 5: Transcranial Duplex Imaging of Case 5

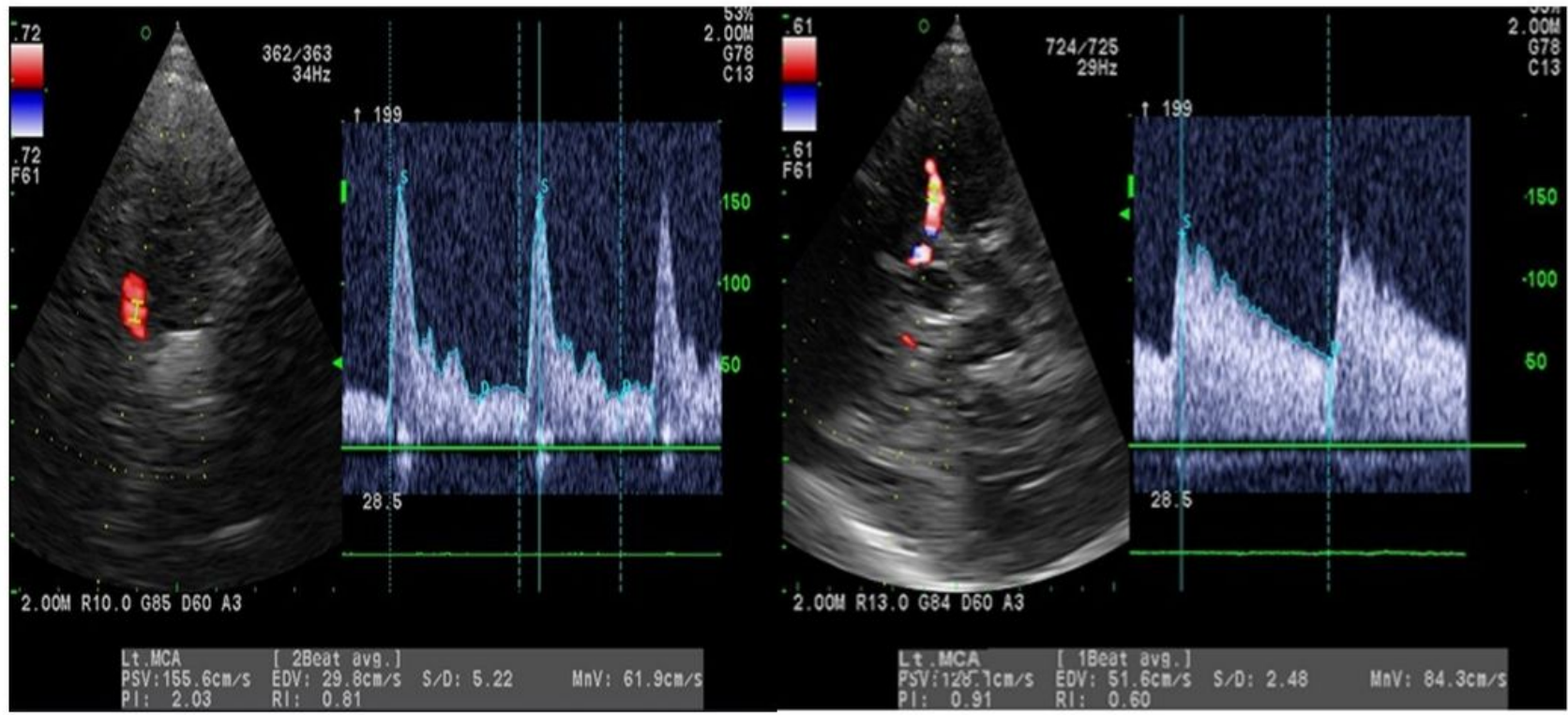

Initial CTCD of left MCA spectrum with systo-diastolic dissociation with hypoperfusion due to high cerebrovascular resistance (MV:61.9 cm/sg,IP:2.03).CTCD after management with normal mean velocity and normal pulsatility index( MV:84.3 cm/sg IP:0.91).

\section{Figure 5}

Initial CTCD of left MCA spectrum with systo-diastolic dissociation with hypoperfusion due to high cerebrovascular resistance (MV:61.9 cm/sg,IP:2.03).CTCD after management with normal mean velocity and normal pulsatility index( MV:84.3 cm/sg IP:0.91).

\section{Supplementary Files}

This is a list of supplementary files associated with this preprint. Click to download.

- WhatsApplmage20210905at5.08.50PM.jpeg 